\title{
Creating a Culture of Risk in Greece Amidst the Economic Crisis: A Brief Retrospect on "Ice Age"
}

\author{
Iordanis Eleftheriadis", Vasilios Vyttas \\ Department of Business Administration, University of Macedonia, Greece
}

Copyright $\bigcirc 2016$ by authors, all rights reserved. Authors agree that this article remains permanently open access under the terms of the Creative Commons Attribution License 4.0 International License

\begin{abstract}
The recent financial crises in America and Europe have shown emphatically that the findings of the relevant risk management literature concluding that lurking risks can be converted into opportunities have unfortunately not informed policy. The assumption of the risk as a burden, often leads economies to crises that undermine the development and prosperity of states and citizens. In this context, this article aims at highlighting risk characteristics and presentation of basic management principles which should govern the operation of public service organizations. Based on literature review of the economic facts of the 2008-2015 period in Greece, the fact that emerges is that effective risk management is a necessary condition for the survival of public organizations in today's global environment.
\end{abstract}

\section{Keywords Risk, Financial Crises, Culture of Risk}

\section{Introduction}

Nowadays, effective public administration constitutes an integral part of economic and social activity, while at the same time it is a determining factor of a country's competitiveness. Without disputing the contribution of the Greek public sector, it is believed that it must be adapted to contemporary global developments with specific interventions. The need to bring the Greek state to the era of efficiency emerges against a backdrop of intense political, environmental and economic risk. On the other hand, the recent financial crises have revealed that states are insufficiently prepared to deal with them. Treating risk as a burden frequently leads economies to crises that undermine growth and prosperity at both an individual and state level. [1] In order to achieve this, the paper is organized as follows: In the first section we approach risk from a theoretical perspective. The section focuses attention on individual as well as organizational behavior in a risk situation. In the second section we highlight the importance of risk-taking in present times, we stress the need to instill risk culture in organizations and analyze the role contemporary managers must have in risk-management. The third section, through an extensive review of the literature focuses on the case of Greece and its failed attempt to manage financial risk. In the fifth section, finally, we summarize the conclusions of the paper.

\section{Main Body of Paper}

\subsection{Risk and Doubt}

Risk is neither a uni-dimensional, nor a sufficiently defined concept. It is, rather, a concept whose meaning varies according to the context in which it is used. Risk is not always a burden, as it is frequently perceived, but rather the necessary condition to bring about change and make the most of opportunities.

In most dictionaries, risk involves a potential adverse outcome. In the Oxford English Dictionary the definition offered is "the possibility of loss, injury, or other adverse or unwelcome circumstance; a chance or situation involving such a possibility". In everyday language, risk typically refers to "exposure to adversity", while, at the same time, is it associated with uncertainty and insecurity.[2] A more comprehensive definition of risk is provided in the ISO 3000 standards. The ISO ${ }^{1} 31000$ (2009) definition of risk is the 'effect of uncertainty on objectives'. In this definition, uncertainties include events (which may or may not happen) and uncertainties caused by ambiguity or a lack of information. It also includes both negative and positive impacts on objectives. Many definitions of risk exist in common usage, however, the value of ISO definition lies in the fact that it was developed by an international committee representing over 30 countries and is based on the input of several thousand subject matter experts.

1 International Organization for Standardization 
The literature contains numerous, frequently contradictory definitions of uncertainty. This weakness is considered to be due to 'lack of information', and incomplete or erroneous knowledge and information. [3,4] According to Mitchel, [4] uncertainty must be examined in relation to the potential losses the organization may suffer as well as their extent for the organization. Uncertainty is considered the source of risk. Had there been no uncertainty, there would be no risk. As Marais [3,p.22] puts it: "we would have known with absolute certainty what would go wrong, when it would happen, and what the consequences would be. With the proper investment in time and resources, we would be able to make fully substantiated decisions regarding our acceptance or not of future events."

In recent years, risk has emerged as a significant variable for businesses and organizations alike. In the relevant literature we find a host of references and analyses related to the impact of risk on managerial decisions and organizational performance. Many researchers focus on managers' effort to avoid risk, [6] others emphasize the multiple dimensions of organizational risk, [6-8] while a number of studies refer to industrial risk and its impact [9] as well as enterprise performance. [10]

\subsection{Behaviors of Organizations and Individuals under Risk}

Organizations and individuals can attach different interpretations to the impact of risk. More specifically, what is seen as loss by an individual or an organization can at the same time be considered a benefit for the other side. Furthermore, tolerance for loss due to a possible risk varies from person to person and across organizations.

In the relevant literature, a number of variables that influence risk-taking behavior have been identified, such as self-confidence, perceived competence and risk propensity. [11-13] With respect to perceived competence, Klein and Kunda [11] observed that individuals' perceived ability to be in control, influenced their decision to be involved in a risk-taking endeavor. Employees who explore and implement creative ideas accept not only the risk involved but also, due to the high possibility of failure, the concomitant responsibilities. [14,15] Yet, there is research that indicates that many employees prefer to participate in controlled risk rather than events or situations well beyond control, in which the risks involved are significantly greater. [11] In both cases, organizational culture may encourage or discourage risk-taking on the part of the manager. [16] Other research studies on decision-making in organizations have indicated that the behavior of individuals in the process of decision-making is partly determined by the extent of possible risk and have attempted to empirically explain what influences this risk. [17]

There are few studies on risk-taking by employees in organizations. In their thorough study of the relevant literature, Neves and Eisenberger [18] found only two other studies (other than their own) on risk-taking by employees.
And yet, interest in the importance of risk-taking has increased dramatically in recent years, [19] with emphasis placed on the managers' propensity to assume or avoid risk. Risk propensity, or rather, orientation to risk, is defined as a general tendency to prefer a risky alternative. $[16,17,20]$ Risk propensity is influenced by whether a certain level of risk can be considered acceptable by an organization, by the overall risk tolerance [21] and tolerance of failure. [22] Risk orientation influences the extent to which organizations perceive a situation as an opportunity or as a threat, the kind of decisions that will be made, and, finally, investments made in order to redistribute resources within an organization. [23]

\subsection{Risk-taking in Organizations}

The field of risk management emerged in the 1990s. In recent years, interest in the field has exploded for a number of reasons. Some factors conducive to the rising research interest are the changes in the competitive international arena, as well as the trend for increasing complexity and unrest. $[24,25]$ This became evident after a series of severe economic and corporate scandals of the 1980s and 1990s. [26]

Successful risk-taking in organizations includes the actions that have uncertain outcome, but potentially high returns. [27] In order to be able to cope with constantly increasing competition on a global scale, and to maximize profits, organizations demand of managers and employees to take initiatives and manage increased risk which may significantly damage the organization in case of failure. Organization risk-taking can be successful in some cases, while in other cases unsuccessful, or even utterly catastrophic. In both cases, the examples are numerous. Neves and Eisenberger [18] provide examples of both successful and unsuccessful risk-taking. Examples of the former are changes brought about by (internet) technology in consumer habits, exchange of information and the formation of relationships, while examples of failures caused by excessive risk-taking are 'the bust of the dotcom bubble of the 1990's and the recent massive bankruptcies in the home mortgage and banking industries'. [18,p.188]

A significant parameter that determines the effort of a risk-bearing organization to survive to a large extent is the ability of managers who bear the responsibility of risk management to understand risk as a source of danger for the organization and to comprehend how significant it is to avert it. For Keough, high-level executive of Coca-Cola Co, risk-taking should be actively pursued by organizations. [28]

\subsection{Risk Management and Culture of Organizations}

Levy, Lamarre and Twining [29,p.3] defined risk culture as "the norms of behavior for individuals and groups within an organization that determine the collective ability and understand, openly discuss and act on the organization's 
current and future risks". Standard \& Poor's [30] highlighted the significance of an organization developing risk culture, advising "risk-bearing" companies "to look beyond the technology, and create risk management culture throughout the organization" and proposing that ERM (enterprise risk management) "must be introduced into existing practices, the behavior of individual managers and the daily decisions they make."

Every organization demonstrates a different culture that can lead it to exceptional performance. Shahzad, Luqman, Khan and Shabbir [31] argue that organizational culture has significant consequences for employees' performance, which can increase productivity and enhance overall organizational performance. Kefela [32] adds that, organizational culture has a significant effect on the way an organization implements its business strategy and achieves its goals.

However, literature is divided concerning the compatibility of organizational and risk management culture. The adoption and implementation of enterprise risk management (ERM) is influenced by various factors. A number of studies point out that risk culture is one of the significant aspects of risk management that members of the Board must comprehend. The reason behind this is that risk management implementation will fail if the risk management culture is not understood by all levers of the enterprise. [33] When it comes to implementing ERM, previous studies consider organizational culture an obstacle and limitation. [34] Kimbrough [35] concurs, as the results of his study showed that organizational culture had a negative impact on the efficiency and speed of deployment of the enterprise risk management.

It is essential that there should be consensus as regards the necessity of instilling a risk culture in organizations. In order to implement a healthy enterprise risk management system, the Board of Directors, as well as management, should make sure that the risk management framework is embedded in the company culture, procedures and structures.

\subsection{The Role of Managers in Risk Management}

Enterprises have acknowledged the possibility of occasional risk within them and have launched manager training programs. There is extensive literature on the subject, in the fields of economics, finance, strategy and international management. [36] Since last decade, risk management has been included in Executive training programs, changing the perception that its use is limited and localized to insurance experts only. [37]

The basic underlying principle of studies in organizational risk is the behavior of the enterprise is a reflection of the behavior of its managers. Thus, the conceptual framework behind the analysis of different results observed in enterprises in the process of decision making is primarily based on an understanding of human behavior. According to Fiegenbaun and Thomas, [38] it is most important to address the question of the extent to which the different behavior of managers in the face of risk can be translated into organizational behavior.

The way a manager perceives risks defines the way he then assesses them. In the literature, there are frequent references to multiple risk assessment methods that identify and focus on the social construction and dimension of risk. $[39,40]$ It is frequently acknowledged, that risk assessment procedures should take more systematic account of the psychological, social, cultural and political dimensions of risk. [41]

\subsection{Risk Assumption}

Recent years have seen a revival of interest in risk management. [42] In the literature the assumption of risks includes the actions which may have uncertain results but potentially high performance. Publishing houses, corporate websites and official organization reports usually include special units with instructions on how organizations should manage risks. A wide array of risks is considered, including financial exposure, information system interruptions, fraud, client bankruptcies and regulatory changes.

The assumption of risk has been extensively studied in contexts such as entrepreneurship,[43] strategic management, [44] consumer behavior, [45] sexual behavior, [46] and decision making processes, and investigation of motives for their assumption. [47] To effectively participate in international competition, which has recently increased, and to effectively increase their profits or citizens' benefits, organizations require from their managers and employees to show initiative and manage increased risks despite the fact that these risks may incur serious economic losses to the organization in case these initiatives fail.

The optimal (level of) danger that maybe assumed by an organization differs significantly depending on the line of work and type of organization. [48] However, risk managers should seriously consider that very low as well as very high risk assumption maybe equally dangerous for the long-term prosperity of the organization. [49] As Neves and Eisenberger [18] state, when organizations and employees assume very low or very high risk, there are serious repercussions for the employees as well as for the organizational effectiveness. Having said that, when risk assumption is used wisely, it can be useful for both new and well established organizations.

\subsection{A Brief Overview of the Global Financial Crisis}

The first phase of the global financial crisis began in August 2007. It was then that the European Central Bank (ECB) started providing liquidity to European banks to help them cope with their losses due to their large exposure to the US market, the support they provided to the dollar and the purchase of American mortgage securities. The global crisis reached its climax in September 2008 with the collapse of 
Lehman Brothers. The severe global financial crisis at the end of 2008 and the beginnings of 2009 shocked Europe as well as the US. [50]

In 2008 and 2009, there was relatively little concern about a European sovereign debt crisis. Instead, the focus turned to the ECB's actions to address the global financial crisis. For its part, the ECB proceeded directly to the following initiatives: along with other major central banks it cut interest rates on short-term deposits in order to secure extensive liquidity of the common currency, and entered into currency swap agreements in order to facilitate European banks' access to liquidity in dollars. But the global economic crisis had asymmetric effects across the euro area. Financial flows between banks ran dry at the end of 2008, with investors repatriating their capital to domestic markets and reassessing their exposure on a global level. [51] This fact had direct consequences on those countries (including Greece) that relied heavily on international short-term debt markets and triggered a broader reassessment of asset values and growth prospects, especially for countries that displayed macroeconomic imbalance. [50] The domino effect had been set in motion.

\subsection{The Greek Public Sector}

Greek public administration is a big and complex system consisting of organizations of different types and sizes, which provide all kinds of state services to the citizens (e.g. health services, educational, insurance, social, financial, developmental, cultural etc.). The central government as well as most of the public organizations is based on the nation's capital even though the "Kapodistria Law" provides the possibility of decentralizing public administration and transferring its jurisdiction to regional and local authorities.

According to the authors of the operational programme "Politeia", in the $21^{\text {st }}$ century Greek Public Administration is still characterized by the well-known pathologies: absence of collective action, lack of meritocracy, irrational management of limited available resources, corruption, inertia, legalism, administrative leveling down, atrophy of disciplinary law, mentality of putting in little effort, duplication of effort, lack of a rational approach to job design. [52] For the reversal of the current situation, that is, for the transformation of the public sector from a rigid and bureaucratic type of organization to a modern and flexible one, the Greek State is taking action.

\subsection{The Economic Crisis in Greece}

Throughout its history, even from the years of the Ottoman Empire, Greece has been linked with severe public debt problems. In fact, it has spent more than half of the years since its 1832 independence from the Ottoman Empire in heavy debt. Economists highlight the deeply rooted characteristics of the Greek economy and society which have prevented sustainable economic growth and have created the conditions for the current crisis. Key characteristics of these conditions are: a wasteful state, large and ineffective public administration, widespread tax evasion, extensive clientelism. [53]

Two additional factors incrementally contributed to the creation of the new post-war economic crisis. First, the dramatic decrease of borrowing costs for Greece since its (preparation for the) adoption of the euro currency. Second, the EU member states are committed to the regulations of the Stability and Growth Pact dictating restriction of budget deficits (to $3 \%$ of GDP) and levels of public debt (to $60 \%$ of GDP) for each state. Lenience in the EU audits, however, led to unrestricted borrowing by the Greek government.

The massive inflow of capital with low interest rates during the 2000's and the international financial crisis of 2008-2009 further deteriorated the structural problems of the Greek economy resulting in non-sustainable public finances. The Greek government took advantage of access to cheap credit to pay state expenses and to counterbalance low tax revenues [53] while borrowed capital was not channeled to productive investments. Instead, capital flow was used to fund current consumption. [53]

\subsection{Parameters that Led to the Greek Crisis}

The Greek crisis is a combination of the financial market upheaval and domestic weaknesses (chronic fiscal and commercial deficits). In order to understand the reasons that led to this unprecedented financial crisis we distinguish two periods: the pre-EMU accession period and the post-EMU accession one.

Greece, between 1993 and 1999, decreased its budget deficit by nine percentage points (of GDP) in order to be able to join the EMU. The country was forced to correct its fiscal imbalances as, due to failure to adapt to a series of hard budget constraints, it faced the risk of being excluded from joining the monetary union. In contrast to the harsh conditions of the pre-accession period, being in the EMU was characterized by the implementation of the Stability Pact, which allowed Greece to violate the letter and spirit of the Pact. In fact, for nine years, between 2000 and 2008, Greece violated consistently the 3\% budget deficit ceiling. [54] These large gaps between pre- and post-accession budgets jeopardized the credibility of Greece in the European context. As Katsimi and Moutos [54] explain, a series of domestic and foreign factors combined with cumulative effect to account for the deplorable condition of the Greek economy. Regarding the negative consequences, they focus on the following:

Firstly, the Maastricht criteria (prerequisites for EU accession) exclusively focused on numerical targets, without paying due attention to the quality of the fiscal adjustment of the accession country. The Greek experience confirms the ephemeral nature of the adjustments that rely excessively on tax increases. From 1993 to 2000, the ratio of tax revenues to GDP increased by about eight percentage points, while the ratio of public spending to GDP remained intact. During the EMU period, and until the time when the global crisis started to affect Greece (2008), the total expenditure was kept 
between $43 \%$ - $45 \%$ of GDP, while tax revenue was on a downward path (42, 9\% in 2000 to $39.6 \%$ in 2007).

Secondly, Greek politicians were slow to implement cuts in expenses, contrary to measures of income tax increase that clearly carried less political cost. Thirdly, the increasing influence of labour unions and employer associations, in combination with the politicization and weakening of the autonomy of the bureaucratic apparatus after 1974 (and especially after 1981), which paved the way for the gradual transformation of Greek state administration from an almost "developing state" to "a state in limbo". Fourthly, the political connections of many civil servants, which were used to facilitate career advancement, shifted the weight of bureaucratic complexity of rules and regulations onto the shoulders of "less significant" citizens. Fifth, the formation of a political culture that was irresponsive to citizens' complaints against civil servants perjury in public administration. Sixth, the gradual weakening of state authority did not go unnoticed by the private sector, which finally "gained control" of public administration and distorted the implementation of economic policy.

\subsection{The Cost of the Greek Crisis}

The risks faced by Greek state organizations are economic as well as operational. In general, risks faced by a country are multiple and may come from the external (primarily financial) or the internal environment. The current crisis has given rise to new risks and serious consequences. The impact of the fiscal crisis in Greece is profound and has contributed to the deterioration of the operation of the public sector and its responsiveness to the citizens' needs. This deterioration is not only reflected on the personnel working in the public sector but also has broader implications concerning its social mission and productivity, in a juncture when, due to the economic crisis, there are intense negative consequences on society. In this section, the effect of contractionary policy on expenditures, employment and benefits is examined. Some features of this period are as follows:

a) In terms of public spending: Over the 2001-2006 period, general government expenses in Greece were on average $45,4 \%$ of GDP as against $46,4 \%$ of the EU average and 47,2 of the Eurozone average. In the following three years and until the beginning of the current crisis, there followed a dramatic increase of public expenses in most EU countries, as well as in Greece. Thus, in 2009 general government public expenses rose at $51.0 \%$ of the GDP for the EU-27 average (Eurozone: $51.2 \%$ ) and at $54.0 \%$ for Greece. In the memorandum period for Greece (2010-12) public expenses on the GDP were restricted to the EU average (2012: 49.3\%). [55]

b) In terms of employment: According to the Ministry of Administrative Reform and E-Governance, in the years 2009-2012, employment in the broad civil sector (including state-owned enterprises as well as uniformed personnel of the military, police, port authority, firefighters, etc.) decreased by $20,8 \%$. Specifically, it has been reduced by
221.143 employees, that is, 194.586 in the narrow public sector and 26.457 in Public Utility companies. Total employment in the civil service dropped from 1.066.729 employees (of whom approximately 125.000 uniformed officers) in 2009, to 776.954 (of whom 68.732 in Public Utility companies) in the first months of 2013. This amounts to $18 \%$ of total employment, diverging from the European average. [55]

c) In terms of social welfare: During the period 1995-2009 the general government in Greece spent smaller amounts (as percentage of the GDP) as compared to the EU-15 average on health, education and social welfare. "This fact reflects the lack of adequate emphasis on public sector functions that are at the center of public policy in other EU-15 states". [56] What is noteworthy, however, is that there is a striking gap between Greece and EU-15 as regards the amount spent on general public services: $11 \%$ of the GDP for Greece, as opposed to $7.1 \%$ of the GDP, which is the EU-15 average.

\section{Conclusions}

The present paper attempted a theoretical approach to the double dimension of risk and the positive externalities that may be produced for an organization given the opportunity. In this light, we highlighted the basic characteristics of risk and its intricate relation to uncertainty in the context of the fiscal crisis in Greece. We also stressed the significance of investigating the impact of risk on organizational strategy, daily decision-making in organizations and performance. A study of the literature showed that organizations may be subject to different kinds of risks, the extent of which and the gravity of their consequences may vary.

The next section investigated the behavior of managers as well as of organizations according to the different definition one may attach to risk, as well as its influence on organizations. Furthermore, we studied variables that affect managers' risk-taking behavior. From recent studies it is revealed that individuals' perceptions regarding their competence to be in control of events affected their decisions to participate in a risk-bearing act. In these cases, organizational culture may encourage or discourage risk-taking on the part of managers and, ultimately, generate the type of company that "knows a lot and does a lot." However, regarding risk-taking on the part of employees, little research has been produced, despite the rising interest in risk-taking as part of strategy.

The last section is a brief account of the unsuccessful attempt of Greece to cope with the risks of exogenous (financial) and endogenous risks (financial, operational, etc.).In support of the above, we mentioned the factors that led to the Greek crisis and the impact it has had on the economy and citizens. Finally, treating creditors as an 'inexhaustible purse' leads contemporary inter-dependent economies to over-borrowing, which then gives rise to financial crises that undermine the growth and prosperity of states and citizens around the world. 


\section{REFERENCES}

[1] World Bank. Risk and opportunity: Managing risk for Development, Washington DC, 2014.

[2] D. Borge. The book of risk, Papazisis Publications, Athens. 2008.

[3] K. Marais. A new approach to Risk Analysis with a focus on Organizational Risk Factors, Massachusetts Institute of Technology, 2005.

[4] V.W. Mitchell. Organizational risk perception and reduction: A literature review, British Journal of Management, Vol.6, 115-133, 1995.

[5] P. Bromiley, K. Miller, D. Rau. Risk in strategic management research, Handbook of strategic management, Blackwell Publishers, 259-288, 2001.

[6] P. Bromiley. Testing a causal model of corporate risk taking and performance, Academy of Management Journal, Vol.34(1),37-59, 1991.

[7] K.D. Miller, P. Bromiley. Strategic risk and corporate performance: an analysis of alternative risk measures, Academy of Management Journal, Vol.33, 756-779, 1990.

[8] K.D. Miller, M.J. Leiblein. Corporate risk-return relations: returns variability versus downside risk, Academy of Management Journal,Vol.39, 91-122, 1996.

[9] M.H. Lubatkin, S. Chatterjee. Extending modern portfolio theory into the domain of corporate diversification: does it apply? Academy of Management Journal, Vol.37, $109-137,1994$.

[10] M.Todd, A. Alessandri, H. Raihan. Khan Market performance and deviance from industry norms: (Mis)alignment of organizational risk and industry risk, Journal of Business Research, Vol. 59,1105- 1115, 2006.

[11] W.M. Klein, Z. Kunda. Exaggerated self-assessments and the preference for controllable risks, Organizational Behavior and Human Decision Processes, Vol. 59, 410-427, 1994.

[12] N. Krueger, P.R. Dickson. How believing in ourselves increases risk taking: perceived self-efficacy and opportunity recognition, Decision Sciences, Vol. 23, 385-401, 1994.

[13] J. Mano. Risk-taking, framing effects, and affect, Organizational Behavior and Human Decision Processes, Vol. 57, 38-58, 1994.

[14] K.J. Klein, J.S. Sorra. The challenge of innovation implementation, Academy of Management Review, Vol. 21, 1055-1080, 1996.

[15] N. Madjar, E. Greenberg, C. Zheng. Factors for radical creativity, incremental creativity, and routine, noncreative performance, Journal of Applied Psychology, Vol. 96, $730-743,2011$.

[16] S. B. Sitkin, A. L. Pablo. Re conceptualizing the Determinants of Risk Behavior, The Academy of Management Review, Vol.17, 9-38, 1992.

[17] S. B Sitkin, L. R. Weingart. Determinants of Risky Decision-Making Behavior: A Test of the Mediating Role of Risk Perceptions and Propensity, Academy of Management Journal, Vol.38, 1573-1592. 1995.

[18] P. Neves, R. Eisenberger. Perceived organizational support and risk taking, Journal of managerial psychology, Vol.29, 187-205,2013.

[19] D.A. Aaker, R. Jacobson. The Risk of Marketing: The Roles of Systematic, Uncontrollable and Controllable Unsystematic, and Downside Risk, Strategy and Risk, Jai Press, Greenwich, Connecticut,83-110, 1988.

[20] A. L. Pablo, S.B. Sitkin, D. B. Jemison. Acquisition Decision-Making Processes: The Central Role of Risk. Journal of Management, Vol.22, 723-746, 1996.

[21] M. R. Walls, J. S. Dyer. Risk Propensity and Firm Performance: A Study of the Petroleum Exploration Industry. Management Science, Vol.42, 1004-1021, 1996.

[22] E. Danneels. Organizational antecedents of second-order competences. Strategic Management Journal, Vol.29, 519-543, 2008.

[23] A.A. Phathak. Effect of Organizational risk orientation and change disposition on dynamic capabilities: An emerging markets perspective, Indian Institute of Management Ahmedabad,1-2,.2013.

[24] C. Chapman, S.Ward. Constructively simple estimating: A project management example. Journal of the Operational Research, 1050-1058, 2003.

[25] A. Giddens. Runaway world: How globalization is reshaping our lives, Routledge, London,2003.

[26] U. Beck. Risk society: Towards a new modernity. Sage, London.1992.

[27] T.H. Chiles, J.F. MacMackin. Integrating variable risk preferences, trust, and transaction cost economics", Academy of Management Review, Vol. 21, 73-99,1996.

[28] D.R. Keough. The Ten Commandments for Business Failure, Penguin Books, London, 2008.

[29] C. Levy, E. Lamarre, J. Twining, Taking control of organizational risk culture, McKinsey\& Company, 2010.

[30] Standard \& Poor's. Enterprise risk management for ratings of nonfinancial corporations. Ratings Direct, 2008.

[31] F. Shahzad, A. Luqman, R. Khan, L. Shabbir. Impact of Organizational Culture on Organizational Performance: An Overview. Interdisciplinary Journal of Contemporary Research in Business, Vol.3,2012.

[32] G.T. Kefela. Understanding organizational culture and leadership-enhance efficiency and productivity, PM World Today, XII(1), 2010.

[33] A. Roslan, H.M. Dahan. Mediating effect of enterprise risk management practices on risk culture and organizational performance. ICSSR: International Conference on Social Science Research, Penang, Malaysia, 2013.

[34] E.A. Kleffner, B.R. Lee, B. Mc Gannon. The effect of corporate governance on the use of enterprise risk management: Evidence from Canada. Risk Management and Insurance Review, Vol.6, 53-73, 2003. 
[35] R.L.Kimbrough. The relationship between organizational culture and enterprise risk management. Engineering Management Journal, Vol.21, 2009.

[36] U. Jutner, H.Peck, M. Christofer. Supply chain Risk Management: outlining an agenda for future research. International Journal of Logistics: Research and Application: A Leading Journal of Supply Chain Management Vol 6, 2003.

[37] J. Cavinato. Supply Chain logistics risks: from de back room to the board room, International Journal of Physical Distribution \& Logistics Management, Vol. 34,383-387, 2004.

[38] A.E. Fiegenbaum, H. Thomas. Attitudes toward risk and the risk-return paradox: prospect theory explanations, Academy of Management Journal, Vol.31,1988.

[39] G. Reith. Uncertain Times: The Notion of "Risk" and the Development of Modernity, Time and Society, Vol.1, 383-402,2004.

[40] G. Mairal. Narratives of Risk, Journal of Risk Research, Vol. 11, 41-54, 2008.

[41] P. Slovic. Trust, Emotion, Sex, Politics, and Science: Surveying the Risk-Assessment Battlefield, Risk Analysis, Vol. 19, 689-701,1999.

[42] B. Scapens, M. Bromwich. Editorial: Risk management, corporate governance and management accounting, Management Accounting Research, Vol.20, 2009.

[43] W.H. Stewart, P.L . Roth. Risk propensity differences between entrepreneurs and managers: a meta-analytic review, Journal of Applied Psychology, Vol. 86, 145-153, 2001.

[44] S.F. Latham, M. Braun. Managerial risk, innovation, and organizational decline, Journal of Management, Vol. 35, 258-281, 2009.

[45] V. Mitchell, A. Nygaard. Consumer perceived risk: conceptualization and models, European Journal of Marketing, Vol. 33, 163-195, 1999.

[46] D.Kirby. The impact of schools and school programs upon adolescent sexual behavior, Journal of Sex Research, Vol. 39, 27-33,2002.

[47] A. Tversky, C.R. Fox. Weighing risk and uncertainty, Psychological Review, Vol. 102, 269- 283, 1995.

[48] F.X. Molina-Morales, M.T. Martinez-Fernandez, V.J. Torlo. The dark side of trust: the benefits, costs and optimal levels of trust for innovation performance, Long Range Planning, Vol. 44, 118-133, 2011.

[49] A.C. Wicks, S.L. Berman, T.M Jones. Toward a conception of optimal trust: moral and strategic implications, Academy of Management Review, Vol. 24, 99-116,1999.

[50] P.Lane. The European Sovereign Debt Crisis, Journal of Economic Perspectives, Vol. 26, 49-68, 2012.

[51] G.M. Milesi, T. Cedric. The Great Retrenchment: International Capital Flows during the Global Financial Crisis., Economic Policy, Vol.26,285-334, 2011.

[52] General Secretariat of Public Administration and Electronic Governance, Operational program Politia, Re-establishing Public Administration, Ministry of Internal Affairs, Athens,2005.

[53] R.M. Nelson, P. Belkin, D.E. Mix. Grecce' s debt crises: Overview, policy responses, and implications, Current Politics and Economics of Europe, Vol.22, 2011.

[54] M. Katsimi, T.Moutos. EMU and the Greek crisis: The political-economy perspective, European Journal of Political Economy, Vol.26, 568-576, 2010.

[55] G. Kouzis, K. Dimoulas, T. Mitrakos, M. Filiopoulou. The impact of restrictive policies on public services, public goods and human resources of public administration, Social Multi-centre Athens, 2013.

[56] G. Argitis, J. Dafermos, M. Nikolaidi. Sovereign debt crisis in Greece: causes and prospects, Labour Institute, Athens, 1-72,2011. 